\begin{tabular}{|c|c|}
\hline Title & Raman Spectra of the A nodic Oxide Film on Titanoum in A cidic Sulfate and Neutral Phosphate Solutions \\
\hline Author(s) & Ohtsuka, Toshiaki; Jiajiu Guo; Sato, Norio \\
\hline Citation & $\begin{array}{l}\text { J. Electrochemical Society, 133(12), 2473-2476 } \\
\text { https://doi.org/10.1149/1.2108452 }\end{array}$ \\
\hline Issue Date & 1986 \\
\hline Doc URL & http:/hdl.handle.net/2115/62179 \\
\hline Rights & $\begin{array}{l}\text { (1) The Electrochemical Society, Inc. 1986. All rights reserved. Except as provided under U.S. copyright law, this work } \\
\text { may not be reproduced, resold, distributed, or modified without the express permission of The Electrochemical Society } \\
\text { (ECS). The archival version of this work was published in J. Electrochem. Soc. } 1986 \text { volume 133, issue 12, 2473-2476. }\end{array}$ \\
\hline Type & article \\
\hline File Information & J.Electrochem.Soc.133,2473-2476(1986), Raman spectra- titanium--.pdf \\
\hline
\end{tabular}

Instructions for use 
19. M. Pourbaix, "Atlas of Electrochemical Equilbrium Aqueous Solutions," Pergamon Press, Ltd., Oxford (1966).

20. C. R. Clayton, A. R. Brooks, K. Doss, and Y. C. Lu, in "Equilibrium Diagrams and Localized Corrosion," R. P. Frankenthal and J. Kruger, Editors, p. 369, The Electrochemical Society Softbound Proceedings Series, Pennington, NJ (1984)

21. M. P. Seah and W. A. Dench, Surf. Interfaces Anal., 1, 2 (1979).

22. C. R. Clayton, K. Doss, and J. B. Warren, "Passivity of Metals and Semiconductors," M. Froment, Editor, p. 585, Elsevier, New York (1983).

23. J. Detourney, L. De. Miranda, and M. Ghodsi, Corros.
Sci., 15, 295 (1975).

24. T. P. Hoar, in "Modern Aspects of Electrochemistry," Vol. 2, J. O'M. Bockris, Editor, p. 280, Butterworth's Science Publishers, London (1950).

25. A. G. Revesz and J. Kruger, in "Passivity of Metals," R. P. Frankenthal and J. Kruger, Editors, p. 137, The Electrochemical Society, Corrosion Monograph Series, Princeton, NJ (1978).

26. K. Doss, A. R. Brooks, and C. R. Clayton, in "Proceedings of 8th International Congress on Metallic Corrosion," Vol. 1, p. 138, National Research Council, Canada, Toronto, June (1984).

27. M. Sakashita, T. Shimakura, and N. Sato, ibid., Vol. 1, 126 (1984).

\title{
Raman Spectra of the Anodic Oxide Film on Titanium in Acidic Sulfate and Neutral Phosphate Solutions
}

\author{
Toshiaki Ohtsuka, Jiaju Guo, ' and Norio Sato* \\ Corrosion Research Group, Faculty of Engineering, Hokkaido University, Sapporo, 060 Japan
}

\section{ABSTRACT}

Laser Raman spectroscopy has been applied under in situ and ex situ conditions to the anodic oxide films formed on titanium at various potentials in neutral phosphate and acidic sulfate solutions. The Raman spectra reveal that the anodic oxide film is primarily composed of an anatase type of ' $\mathrm{TiO}_{2}$. From the relation between the Raman band intensity, film thickness, and surface morphology, it is likely that the film changes from the amorphous state to the crystalline state beyond a certain critical potential.

In our previous work (1) the anodic oxide film on titanium was examined with respect to the film thicknesspotential relation, polarization curve, and surface morphology in solutions of sulfuric acid, hydrochloric acid, and sodium phosphate. In the work, it was found that a kind of breakdown of the film occurred at a critical potential of $7.5 \mathrm{~V}$. In the potential region more negative than the breakdown potential, $E_{\mathrm{h}}$, the film grew linearly with potential at a thickness-potential ratio of about 2.5 $\mathrm{nmV} \mathrm{V}^{-1}$, while, in the potential region more positive than $E_{\mathrm{b}}$, the film thickness increased at a higher ratio, giving rise to surface roughening.

In this paper the anodic oxide film is further studied by in situ Raman scattering spectroscopy to check its composition. In situ Raman spectroscopy is one of the promising methods for checking the composition of electrode surface layers $(2,3)$. For some special electrode systems, such as silver with pyridine absorbers, surfaceenhanced Raman scattering (SERS) can be used. With the present titanium electrodes, the SERS effect cannot be expected to occur and, therefore, normal Raman scattering spectroscopy, which is not sensitive enough to detect a surface oxide layer as thin as $10 \mathrm{~nm}$, has to be used. In this paper, application of normal Raman spectroscopy to anodic surface oxide films on titanium is discussed in terms of the composition and crystallinity of the films.

\section{Experimental}

The Raman spectrometer used was a triple type of monochromator, JASCO R-800T, and excitation was made by a single line of $514.5 \mathrm{~nm}$ wavelength of an argon ion laser, NEC M-GLS 3200. The incidence power of the line was about $300 \mathrm{~mW}$. The intensity of the scattering light was detected by a photomultiplier and a photon counter.

Figure 1 shows the experimental cylindrical cell for the Raman spectroscopic measurements of electrodes. In the cell, the Luggin tube leading to a reference electrode $\mathrm{Ag} / \mathrm{AgCl}$, and the counterelectrode of a platinum plate were inserted. The working electrode of titanium was fixed at the center of the cell, facing an optical

*Electrochemical Society Active Member

Permanent address: Beijing University of Iron and Steel Tech nology, Beijing, China. window at a distance about $5 \mathrm{~mm}$. The laser light for excitation was polarized in the parallel direction to the incidence plane and its incidence angle was about $50^{\circ}$. The Raman scattering light was collected in the incidence plane in a direction at about $70^{\circ}$ to the incidence light.

The electrolytes used were $0.1 \mathrm{~mol} \mathrm{dm} \mathrm{dm}^{-3}$ aqueous phosphate buffer solution at $p \mathrm{H} 6.9$ and $0.1 \mathrm{~mol} \mathrm{dm}^{-3}$ aqueous sulfuric acid solution, which were prepared from doubly distilled water and analytical grade reagents. The electrolytes were bubbled by purified nitrogen gas for more than $24 \mathrm{~h}$ before being introduced into the cell for experiments. The pretreatment of the titanium electrode $(99.9 \%$ pure) was the same as that described in our previous paper (1).

\section{Results}

Figure 2 shows in situ Raman spectra of the anodic oxide films formed on titanium by $1 \mathrm{~h}$ oxidation at constant potential at $5.60 \mathrm{~V}$ and $10.60 \mathrm{~V} v s$. RHE in neutral phosphate solution of $p H$ 6.9. During these Raman scattering

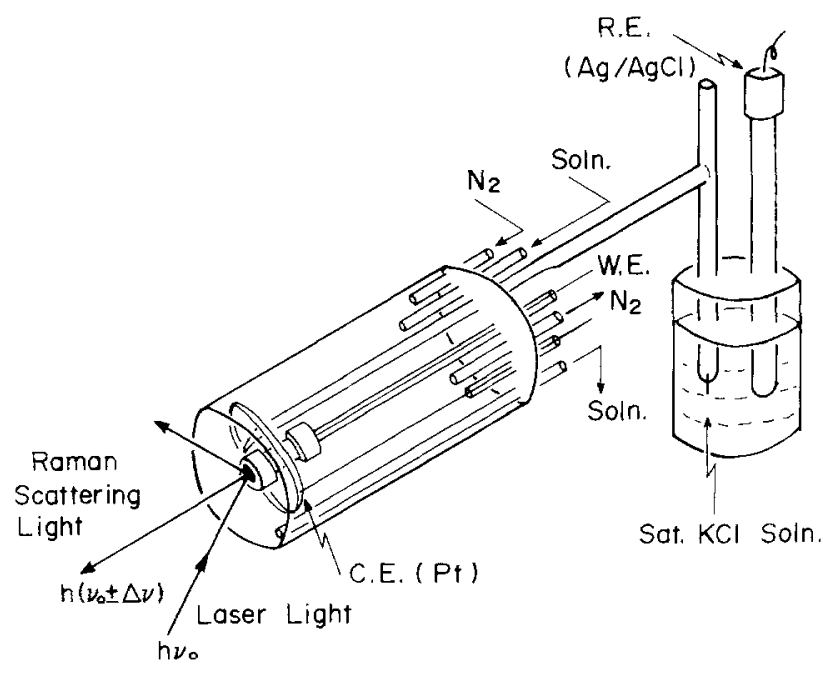

Fig. 1. Electrochemical cell for Raman spectroscopic measurements of the electrode surface layer. 


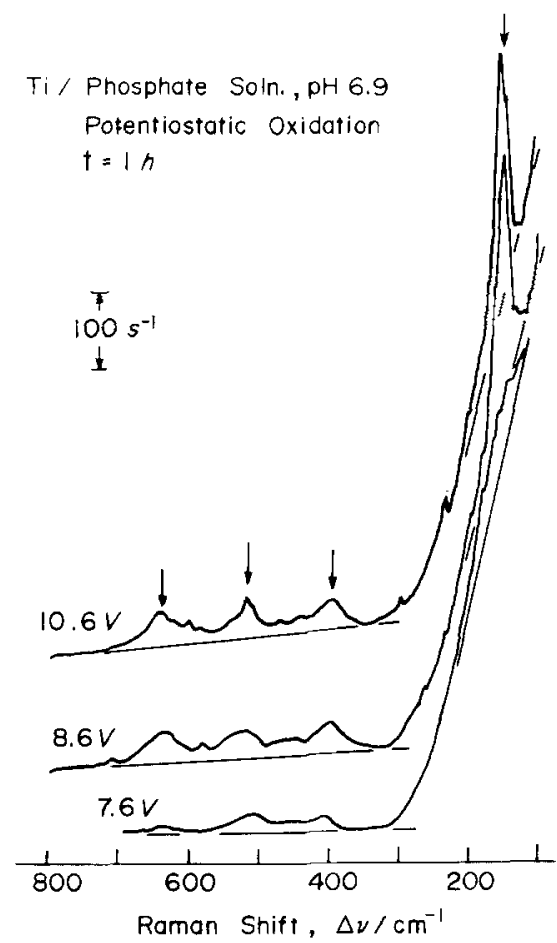

Fig. 2. In situ Raman spectra of the anodic oxide films formed on titanium at constant potentials in $0.1 \mathrm{~mol} \mathrm{dm^{-3 }}$ neutral phosphate solution. The spectra were measured under the potentiostatic condition at $1.60 \mathrm{~V}$ vs. RHE after the specimen was anodically oxidized for $\mathrm{lh}$ at constant potential. The bandposs of the spectrometer was about $5 \mathrm{~cm}^{-1}$.

measurements, the titanium electrodes that had been oxidized for $1 \mathrm{~h}$ at the above potentials were kept at a constant potential of $1.60 \mathrm{~V}$ to avoid evolution of oxygen bubbles, which prevents accurate optical measurements of the electrode surface at potentials higher than $4 \mathrm{~V}$. The Raman spectra of the anodic oxide films formed in 0.1 mol cm-3 sulfuric acid were also measured and the results are given in Fig. 3. In Fig. 2 and 3, four Raman peaks are seen at Raman shifts of $145,400,515$, and 640 $\mathrm{cm}^{-1}$. In Table I, comparison is made between the Raman spectra measured in this work and those found in literature (4-7) for various titanium oxides. From Table I, the anodic oxide film is identified with an anatase type of $\mathrm{TiO}_{2}$. In situ Raman spectroscopic measurements were

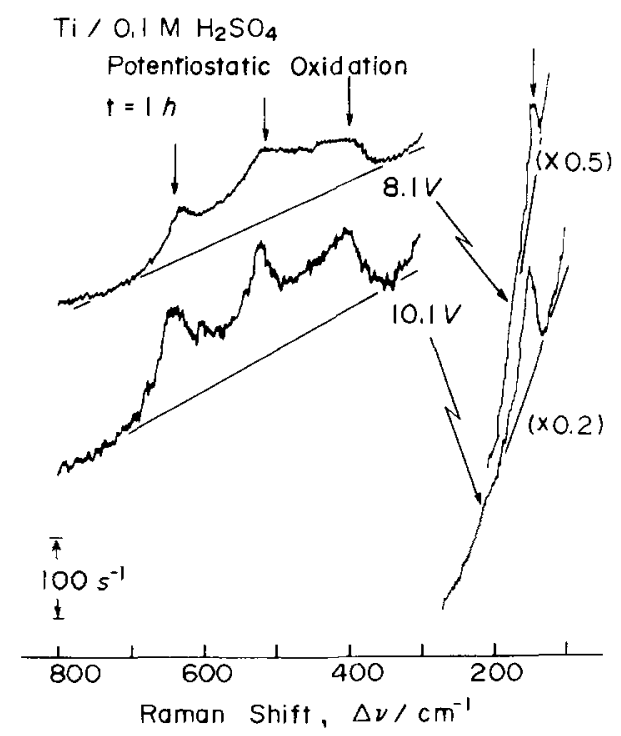

Fig. 3. In situ Raman spectra of the anodic oxide films formed on titanium at constant potential in $0.1 \mathrm{~mol} \mathrm{dm}^{-3}$ sulfuric acid solution. The spectra were measured under the potentiostatic condition at $1.60 \mathrm{~V}$ vs. RHE after the specimen was anodically oxidized for $1 \mathrm{~h}$ at constant potential. The bandpass of the spectrometer was about $5 \mathrm{~cm}^{-1}$.
Table I. Peak position of Raman bands for various titanium oxides

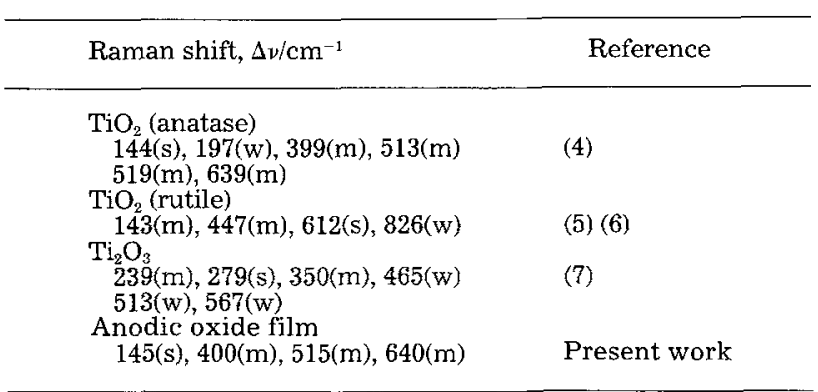

s:strong, m:medium, w:weak.

also made for the anodic oxide films formed at potentials more negative than $7 \mathrm{~V}$ in the phosphate and sulfuric acid solutions, but no definite peaks were detected on the spectra, where only the weak Raman bands corresponding to the aqueous solutions were observed as a background.

The ex situ measurements of the Raman spectra in air were conducted after the anodic oxidation and the results were compared with the in situ spectra. Figures 4 and 5 show the spectra thus obtained for the anodic oxide film formed at potentials lower than $8 \mathrm{~V}$ and at potentials higher than $8 \mathrm{~V}$, respectively. For the oxide formed at potentials higher than $8 \mathrm{~V}$ four relatively intense peaks are seen in Fig. 5, and the peak intensity becomes smaller, the lower the potential.

For the oxide formed at $2.6 \mathrm{~V}$ the four Raman bands corresponding to the anatase type of $\mathrm{TiO}_{2}$ are not distinguishable on the spectrum where only the Raman bands corresponding to air and to optical elements such as condenser lenses are observed. The ex situ spectra of the anodic oxide film formed in sulfuric acid solution were also measured and results similar to Fig. 4 and 5 were obtained.

\section{Discussion}

The intensity of Raman bands of a thin transparent oxide film on a metal surface is supposed to be almost proportional to the thickness of the film. In Fig. 6 , comparison is made between the intensity of the Raman peak at $\Delta v=145 \mathrm{~cm}^{-1}$ and the film thickness found in the previous work (1), where the peak height as the intensity and

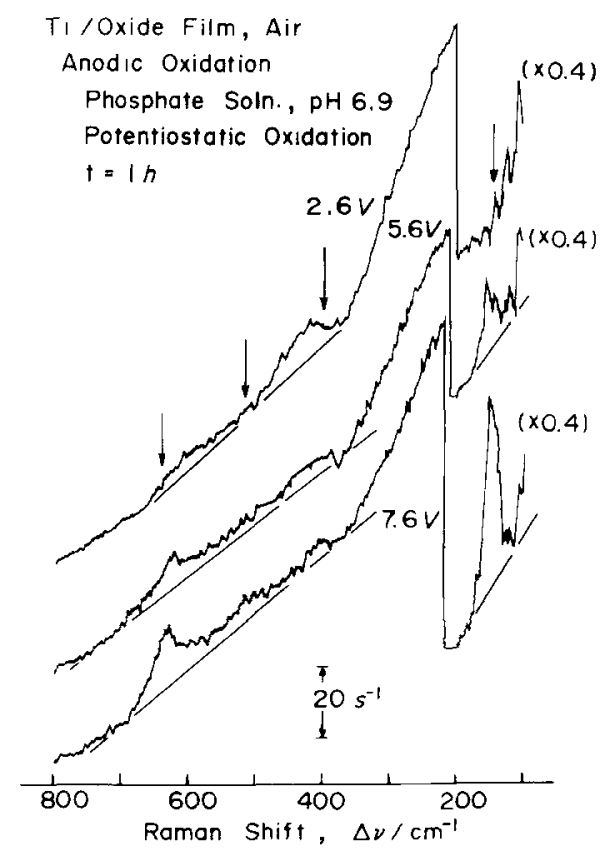

Fig. 4. Ex situ Raman spectra of the anodic oxide films formed on titanium at constant potential for $1 \mathrm{~h} \mathrm{in} 0.1 \mathrm{~mol} \mathrm{dm}^{-3}$ neutral phosphate solution. The bandpass of the spectrometer was about $10 \mathrm{~cm}^{-1}$. 


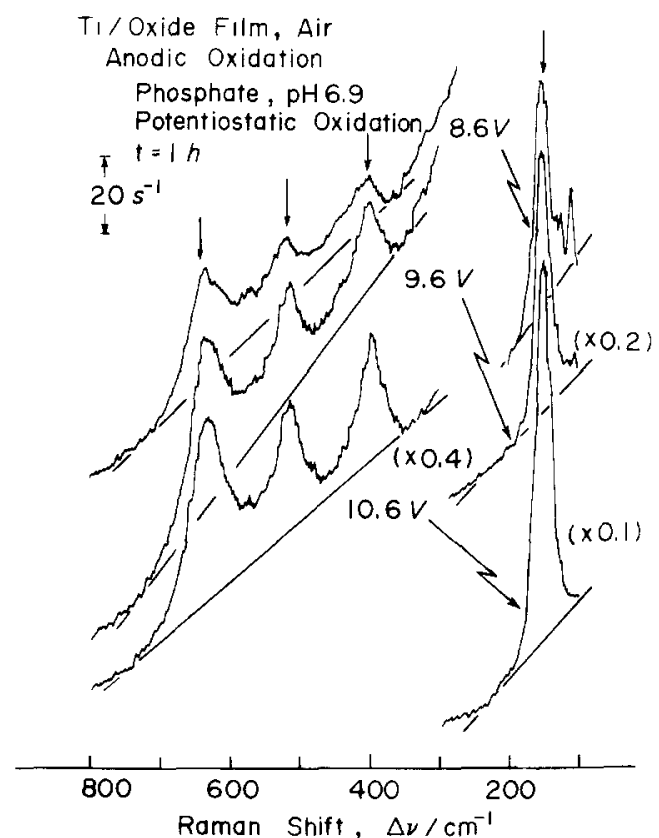

Fig. 5. Ex situ Raman spectra of the anodic oxide films formed on titanium at constant potential for $1 \mathrm{~h}$ in $0.1 \mathrm{~mol} \mathrm{dm}^{-3}$ neutral phosphate solution. The bandpass of the spectrometer was about $10 \mathrm{~cm}^{-1}$.

the thickness are plotted against potential. The data of Fig. 6 for the Raman peak height are based on the results shown in Fig. 4 and 5 . The peak height, estimated in counts/s from subtracting the background level of the spectrum, is reproducible within an error limit of about $20 \%$ at each measurement. The Raman peak begins to appear at about $4 \mathrm{~V}$, and its intensity increases with potential. At a potential of $4 \mathrm{~V}$, although the film thickness is about $13 \mathrm{~nm}$, no definite Raman bands are observed. This suggests that the Raman intensity of the oxide film is determined not only by its thickness but also by other factors. We believe that one of these factors is the crystallinity of the oxide film. The oxide film appears to change from an amorphous to a crystalline state as the potential exceeds a certain value. The amorphous nature

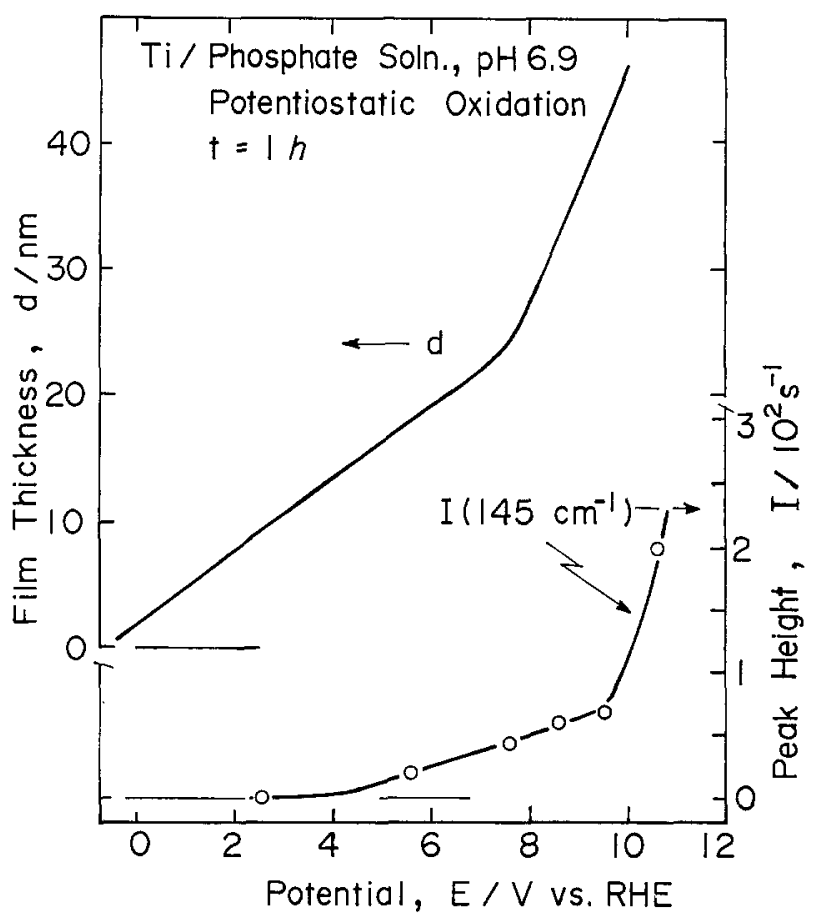

Fig. 6. Film thickness and Raman peak height at $\Delta v=150 \mathrm{~cm}^{-1}$ as a function of potential. The film thickness data were referred to the previous work (1).

of solid compounds brings about Raman bands, which are broader than those of the crystalline compounds, and thus results in the loss of peak sharpness.

Figure 7 shows the surface morphology observed by electron microscopy using a replica technique. In the low potential region, the surface exhibits a similar morphology to that of the polished surface. When the titanium electrode is oxidized at $5.6 \mathrm{~V}$, a crater-like pattern is observed with each crater having a diameter about $3 \mu \mathrm{m}$. When the titanium electrode is oxidized at potentials more positive than $10 \mathrm{~V}$, a ripple-like pattern appears on the electrode surface. The change of the surface mor-

\section{Ti/Phosphate Soln. $\mathrm{pH} 6.9$ I $h$ Oxidation}
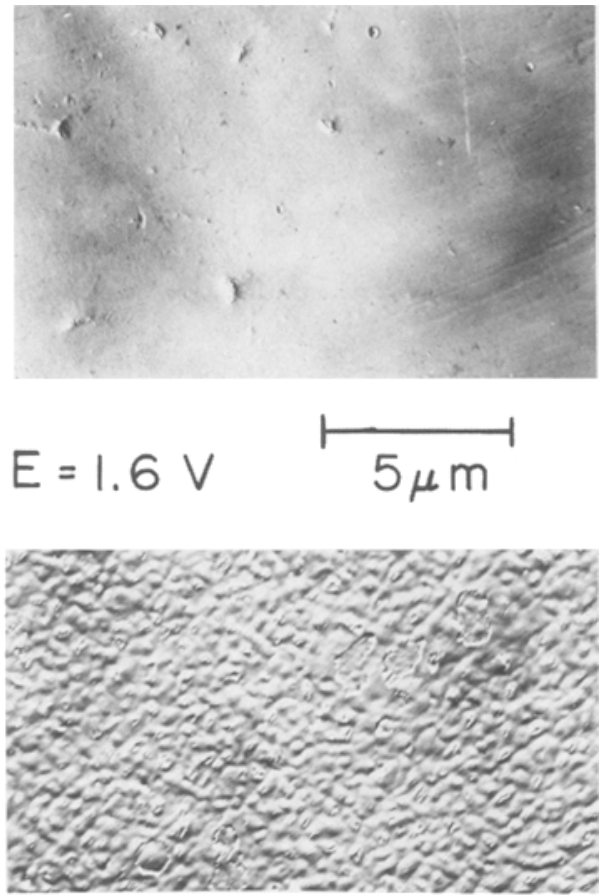

Fig. 7. Electron microscopic appearance of the surface of titanium covered with the anodic oxide film. The oxidation was made potentiostatically for $1 \mathrm{~h}$ in $0.1 \mathrm{~mol} \mathrm{dm}^{-3}$ neutral phosphate solution.

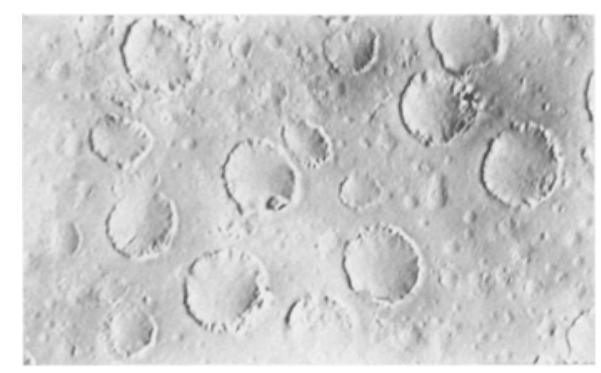

$E=5.6 \mathrm{~V}$

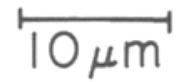

$E=12.6 \mathrm{~V}$

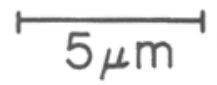


phology is considered to reflect the change from amorphous to crystalline nature of the film, as discussed in the previous work (1). Here, we notice that the potential where the Raman bands begins to appear is closely related to a potential where the crater-like morphology begins to be observed, and that the oxide film that exhibits the ripple-like morphology provides the strong Raman bands of the anatase type of $\mathrm{TiO}_{2}$. This identification of the film composition is in agreement with the results of electron diffraction measurements conducted by Blondeau et al. (8), although the potential region is different from our potential region. They detected a diffraction pattern corresponding to the anatase $\mathrm{TiO}_{2}$ for the anodic oxide film formed at potentials more positive than $50 \mathrm{~V}$ for a much shorter time than that in our experiments and a diffraction pattern corresponding to a quasiamorphous structure at more negative potentials.

\section{Conclusion}

From Raman spectroscopy measurements of anodic oxide films on titanium, the following conclusions may be drawn. (i) The anodic oxide film on titanium is primarily composed of an anatase type $\mathrm{TiO}_{2}$. (ii) The intensity of the Raman band is not directly related to film thickness, and it is suggested that the nature of the film changes from the amorphous to the crystalline oxide as the potential exceeds a certain value. This change is also accompanied by a change in surface morphology.

\section{Acknowledgment}

The authors wish to thank Mr. Noboru Goto and Mr. Minoru Masuda of the Faculty of Engineering, Hokkaido University, for their assistance.

Manuscript submitted Jan. 27, 1986; revised manuscript received May 20, 1986.

Hokkaido University assisted in meeting the publication costs of this article.

\section{REFERENCES}

1. T. Ohtsuka, M. Masuda, and N. Sato, This Journal, 132, $787(1985)$

2. R. J. Anderson and J. C. Hamilton, in "Proceedings of the 9th International Conference on Raman Spectroscopy," p. 239, The Chemical Society of Japan, Tokyo (1984).

3. C. A. Melendres and S. Xu, This Journal, 131, 2239 (1984).

4. T. Ohsaka, F. Izumi, and Y. Fujiki, J. Raman Spectrosc., 7, 321 (1978).

5. S. P. S. Porto, P. A. Flaury, and T. C. Damen, Phys. Rev., 154, 522 (1967).

6. I. R. Beattie and T. R. Gilson, Proc. R. Soc. London, Ser. $A, 307,407$ (1968).

7. S. H. Shin, R. L. Aggarwal, and B. Lax, Phys. Rev. B, 9, 583 (1974)

8. G. Blondeau, M. Froelicher, M. Froment, A. Hugot-Le Goff, M. Brien, R. Calson, and P. Larroque, J. Microsc. Spectrosc., 2, 27 (1977); G. Blondeau, M. Froelicher, M. Froment, and A. Hugot-Le Goff, Thin Solid Films, 42, 147 (1977).

\title{
Corrosion-Related Aspects of the Chemistry and Frequency of Occurrence of Precipitation
}

\author{
T. E. Graedel \\ AT\&T Bell Laboratories, Murray Hill, New Jersey 07974
}

\section{ABSTRACT}

Surfaces exposed to the atmosphere receive water in several forms: adsorption of water vapor, condensation of dew and fog, and deposition of rain and snow. The natural deterioration of wetted materials is enhanced by the corrodents contained in the water as well as by gaseous molecules subsequently incorporated into the water. This paper reviews the chemistry of the different atmospheric precipitation forms, combines those data with typical annual durations of the precipitation forms in four cities (Albuquerque, Los Angeles, Minneapolis-St. Paul, and New York), and deduces the contribution of each precipitation form to annual exposures of materials surfaces to corrodents. A limited assessment for indoor corrodent gases is also included. Among the results of interest are that the nitrate exposure of surfaces appears to be predominantly due to gaseous deposition, that deposition of organic corrodents is as high or higher indoors than it is outside, that materials exposure to the sulfate ion may occur more from dew than from other forms of precipitation, and that under some circumstances fog, rain, and perhaps snow can contribute substantial fractions of corrodent exposure burdens.

It is well established that materials of many different kinds are degraded upon exposure to the atmosphere. It is less obvious how that degradation takes place and what forms of atmospheric impacts play the principal roles. This uncertainty results from the wide ranges in frequency of occurrence of atmospheric phenomena, as well as substantial chemical diversity among those phenomena when they do occur.

A common thread in the several atmospheric processes that degrade materials is that the processes are markedly accelerated by water (1). This water may be provided by any of the several forms of precipitation or by the adsorption of water vapor during periods of moderate to high humidity (2). In the former case, the water brings with it any corrodents that may be present in precipitation. In both the former and latter cases gas phase corrodents may become incorporated into water that is present at the surfaces of the materials.

The purpose of the present study is to compare the exposures of materials to corrodents from six sources: dew, fog, rain, snow, gaseous molecules in outdoor air, and gaseous molecules in indoor air. The first step in doing so is to review the frequency of occurrence of the meteoro- logical phenomena, as summarized in Table I. There are, of course, wide ranges of moisture deposition amount and of the duration of the atmospheric processes. It is worth noting in Table I that dew and fog typically deposit similar amounts of moisture to a surface, as do rain and snow (in climates where both occur).

Precipitation contains a number of trace constituents which have the potential to produce materials degradation. Partly because of their known interactions with materials and partly because of the availability of sufficient

Table I. Occurrence of atmospheric phenomena at mid-latitude North American sites

\begin{tabular}{lccccc}
\hline & $\begin{array}{c}\text { Annual moisture } \\
\text { deposition (mm) } \\
\text { Typical } \\
\text { value }\end{array}$ & $\begin{array}{c}\text { Annual duration } \\
\text { (h) } \\
\text { Typical } \\
\text { Phenomenon }\end{array}$ & Range & $\begin{array}{c}\text { value } \\
\text { References }\end{array}$ & Range \\
\hline Dew & $0-100$ & 30 & $0-1500$ & 750 & $(3-7)$ \\
Fog & $0-40$ & 25 & $0-150$ & 60 & $(7),(8)$ \\
Rain & $30-6500$ & 700 & $10-3000$ & 300 & $(9)$ \\
Snow & $0-9000$ & 750 & $0-3000$ & 300 & $(9)$
\end{tabular}

